\title{
Perceptions and Suggestions of II year M.B.B.S. Students Regarding Updated Pathology Teaching Curriculum: An Analytic Study
}

\author{
Kumar U. M. ${ }^{1}$, Ramesh Pande P. ${ }^{2 *}$, Prasanna S. ${ }^{3}$ \\ DOI: https://doi.org/10.17511/ijmrr.2019.i02.15 \\ 1 Mahesh Kumar U., Professor \& HOD, Department of Pathology, Mahavir Institute of Medical Sciences, Vikarabad, Telangana, India. \\ 2* Pankaj Ramesh Pande, Associate Professor, Prakash Institute of Medical Sciences, Urun Islampur, Sangli, Maharashtra, India. \\ 3 S. Sai Prasanna, Undergraduate Medical Student, Prathima Institute of Medical Sciences, Karimnagar, Hyderabad, India.
}

Introduction: In most of the medical colleges of India, the knowledge regarding basic science subjects is taught mainly through didactic lectures, tutorials and practicals. And hence the system is more of teacher centered with less interaction or involvement from the students. There is a need to explore innovations, so as to sustain interest. Objectives: To introduce interactive teaching and assessment methods during lectures and examinations respectively and to elicit student's perception about them. Materials and Method: A number of interactive methods were introduced in the pathology curriculum in a batch of 153 medical students of $2^{\text {nd }}$ year M.B.B.S. Later the perceptions of the students were elicited regarding these sessions using a questionnaire based on Likert scale. Results: Validation of the scale indicated good internal consistency with Crohnbach's alpha coefficient of 0.9 . Majority $(83 \%)$ of the students agreed or strongly agreed to like the interactive sessions. Similarly, $86 \%$ agreed or strongly agreed to like teamwork in group discussions and quiz sessions. Most popular interactive mode was MCQ's followed by Cinemeducation. Most students were also of the view that interactivity during lectures keeps them active, more attentive in the class, makes the atmosphere more lively, also improved their communication skills, helps in retention of the topic, clearing doubts, improves attention span and hence results in better understanding of the subject. Conclusion: This project clearly proves that updated pathology curriculum is preferred by students. So, teacher should take a new role of facilitating the process of interactive learning rather than delivering elaborative lectures.

Keywords: Interactive teaching, Multiple choice questions, Pathology

Corresponding Author

Pankaj Ramesh Pande, Associate Professor, Prakash Institute of Medical Sciences, Urun Islampur, Sangli, Maharashtra, India.

Email: pathology2019@yahoo.com
How to Cite this Article

Kumar UM, Pande PR, Prasanna SS. Perceptions and

Suggestions of II year M.B.B.S. Students Regarding Updated Pathology Teaching Curriculum: An Analytic Study. Int J Med Res Rev. 2019;7(2):143-149. Available From https://ijmrr.medresearch.in/index.php/ijmrr/article/ view/1048
To Browse

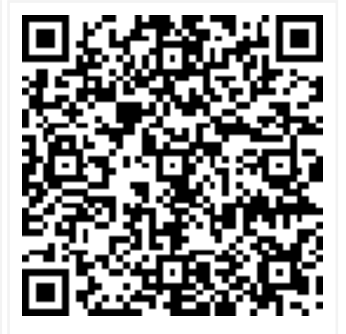

Manuscript Received 2019-04-05

Conflict of Interest No
Review Round 1 2019-04-14

Funding

Nil
Review Round 2

2019-04-20

Yes
Ethical Approval
Review Round 3

Plagiarism X-checker $9 \%$
Accepted 2019-04-26

(c) 2019 by Mahesh Kumar U., Pankaj Ramesh Pande, S. Sai Prasanna and Published by Siddharth Health Research and Social Welfare Society. This is an' Open Access article licensed under a Creative Commons Attribution 4.0 International License https://creativecommons.org/licenses/by/4.0/ unported [CC BY 4.0]. 


\section{Introduction}

Most important task for any teaching professional is to impart meticulous knowledge to learners. As far as medical education is concerned, it is vital to use best available expertise in teaching methodology [1]. Understanding the concepts taught in basic science subjects serves as a backbone for studying the clinical sciences [2].

Second professional year in the medical undergraduate is the pedestal where the students start attending clinics. Theoretical teaching will be of great help to make their fundamentals clear. Variation in the teaching methods is necessary as per the need. Medical Council of India has made arrangement of training of medical faculties by organizing medical educational units in all medical colleges.

Regular sessions are being conducted all over the country by the medical education units [1]. In most of the medical colleges of India, the knowledge regarding basic science subjects is taught mainly through didactic lectures, practical's, and hence the system is more of teacher centred with less interaction or involvement from the students [3].

Lecture is considered the most cost-effective method in comparison with other teaching learning methods. However, attention span studies have shown that students' attention decreases significantly after $20 \mathrm{~min}$ in traditional lectures. Introducing interactivity in the lecture breaks the monotony and stimulates interest resulting in improved attention.

Lecture imparts a great deal of information quickly and effectively to a large number of students. Tutorials, seminars and other student centered learning have been used to Complement lectures which are viewed as interactive components. However, in recent years, efforts are taken to make the lecture more effective by using various interactive methods.

There is a need to explore innovations in planning lectures so as to sustain interest. This can be achieved by implementation of student-centred programs like role plays, seminars, tutorials, quiz competitions, group discussions, integrated teaching and Cinemeducation. Interactive teaching is very important for medical students where the retention and recall of information is needed for its application in clinical practice.
The undergraduate medical curriculum should be such that it should train the undergraduates to undertake the responsibilities of a physician of first contact who is capable of looking after the preventive, promotive, curative and rehabilitative aspects of medicine [3].

As a part of program evaluation, usually feedback on curriculum is obtained by subject experts from other universities. There is an unmet need to obtain the perceptions of the undergraduates as they represent one of the important stakeholders [3].

Hence in this context, our study was planned with an aim to introduce interactive teaching and study its effectiveness using questionnaire by collecting the perception and also their suggestions regarding the revised pathology curriculum.

\section{Aims \& Objectives}

01 . To introduce interactive sessions in teaching and assessment methods during lectures and examinations respectively

02. To elicit student's perception about its effectiveness

03. To gather the suggestions from the students in the form of responses to open end questions

\section{Materials and Methods}

Place of Study: Prathima Institute of Medical Sciences and Hospital, Karimnagar, Telangana State.

Type of Study: This was a cross sectional study

Duration of Study: 21st June to 21st Aug 2016 (Two months duration)

Study population: The study included II year MBBS students

Sample size: 153 students (Since only II Year MBBS Students were involved)

Inclusion Criteria: Students who will fill and return the feedback questionnaire will be included in the study.

Exclusion Criteria: Students who will not fill and return the feedback questionnaire will be excluded from the study.

Data analysis: Obtained data was checked for error and then data entry was completed and finally data was analyzed by using recent SPSS software. 
Perceptions of the students were elicited regarding these sessions using a questionnaire based on Likert scale, which was validated in a pilot study. Validation of the scale indicated good internal consistency with Crohnbach's alpha coefficient of 0.9. Results were illustrated using bar charts and pie charts.

Ethical consideration: The study protocol has been approved by the Institutional Ethics Committee for ethical approval.

Method of collection of data: The data was collected using an anonymous pre-designed questionnaire. Discussions were carried out with the head of the department and other faculty members regarding the project and their valuable inputs were taken in preparation of questionnaire. A series of interactive methods such as small group discussions, Cinemeducation, integrated teaching, multiple choice questions (MCQ's), question answer sessions, seminars, Quiz, and summaries were introduced in the pathology curriculum for 153 medical students of 2 nd year M.B.B.S at appropriate intervals. And during formative assessment sessions "Playing Card type" - Viva-voce examination was undertaken. In which there were 20 questions. These questions were divided into Must to know, desirable to know and nice to know. Must to know questions accounted for 14 questions, desirable to know accounted for 4 questions and nice to know questions accounted for 2 questions. Playing Cards were made for each question. Student should pick 7 cards from a bunch of 14 cards of must to know, 2 cards from desirable to know and one card from nice to know. Whole viva-voce was given 10 marks.

There were four quiz competitions. First was general pathology, second was haematology, third was systemic pathology and last quiz was a Grand quiz and participants who won previous quiz's were choosen.

\section{Questionnaire}

\section{Feedback Form}

\section{Date:}

Please answer the following by ticking in the appropriate box.

$\mathbf{A}=$ Strongly Agree, $\mathbf{B}=$ Agree, $\mathbf{C}=$ can't say, $\mathbf{D}=$ Disagree and $\mathbf{E}=$ Strongly Disagree

\begin{tabular}{|l|l|l|l|l|l|}
\hline \multicolumn{1}{|c|}{ Questions } & A & B & C & D & E \\
\hline 1. Enjoyed the interactive lecture & & & & & \\
\hline 2. Appreciation of different types of interactivities & & & & & \\
\hline
\end{tabular}

\begin{tabular}{|l|l|l|l|l|l|}
\hline MCQ's & & & & & \\
\hline Cross-word puzzle & & & & & \\
\hline Jig-saw learning & & & & & \\
\hline Integrated teaching & & & & & \\
\hline Quiz & & & & & \\
\hline Viva-voce & & & & & \\
\hline Cinemeducation & & & & & \\
\hline 3. Advantages of interactivity & & & & & \\
\hline Communication skills develop due to interactive & & & & & \\
\hline Sessions & & & & & \\
\hline Role interactivity in retention of subject & & & & & \\
\hline
\end{tabular}

Your suggestions on Interactive teaching and learning process

01.

02.

Your comments on Interactive teaching and learning process

01.

02.

Statistical Analysis: Percentages were used to summarize the categorical outcomes. Mean and Standard Deviation (S.D) were used to summarize the numerical outcomes.

\section{Results}

Pre-validation of the questionnaire: Pilot testing was done on 10 (ten) II year MBBS students who were asked to opine regarding the content, consistency and clarity of the questionnaire. Necessary modifications were made as per the feedback given by the students.

The pre-validated questionnaire based on 5- point Likert scales, ranging from strongly disagree to strongly agree was administered to the study sample to elicit their perceptions on the interactive sessions they had attended, after taking written informed consent and institutional ethical committee approval. Out of 153 II year MBBS students, 146 interns returned the questionnaire.

Reliability of the questionnaire: The reliability of the questionnaire was done by calculating the chronbachs alpha which showed the value of 0.901 indicating a highly reliable one.

The interactive lectures were liked and enjoyed by $88 \%$ students [Table 1]. Nearly $92 \%$ agreed or completely agreed to like teamwork in small group discussions (Jig-saw learning, cross-word puzzle,) and quiz sessions. 
The MCQs were liked by most of the students, followed by jig-saw learning and cross-word puzzle [Table 2]. The students felt that interactivity improved their communication skills, added to the retention of the knowledge, improved the attention span during the lecture and hence recommended its use for all other lectures [Table 3]. Only few students noted that it is time consuming and syllabus will not get completed. For traditional lectures, students felt that they are monotonous, continuous and difficult to concentrate beyond 20$30 \mathrm{~min}$. They felt that interactivity keeps them active and more attentive in the class, makes the atmosphere lively and hence results in better understanding of the subject, more retention of the facts and also helps in clearing doubts. The students were satisfied and happy with this new method of learning and suggested that other lectures should also be conducted in a similar manner.

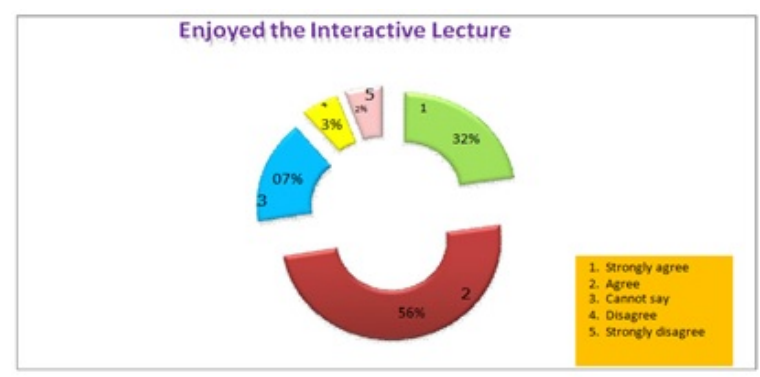

Fig 1: Likert scale for enjoying the interactive lecture

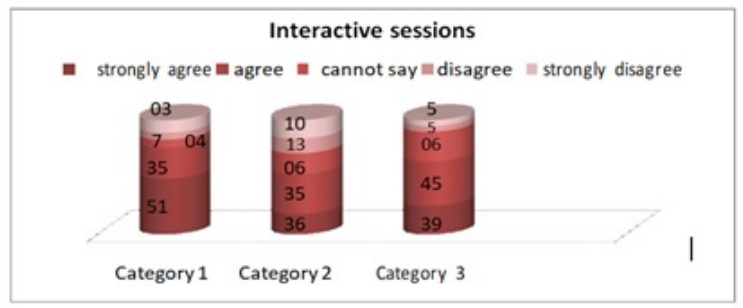

Fig 2: Comparison of appreciation of different types of interactivities

Category 1: MCQ (86\%) Category 2: Cross-word puzzle (71\%) Category 3: Jigsaw learning (84\%)

Yellow colour: Strongly agree

Green Colour: Cannot say

Red Colour: Agree

Dark Blue Colour: Disagree

Sky blue Colour: Strongly disagree

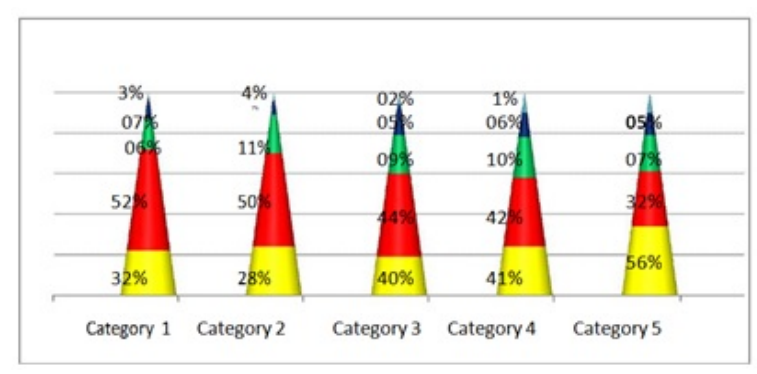

Fig 3: Likert scales showing various advantages of interactivity

Category 1: Communication skills develop due to interactive sessions (Agree: 84\%)

Category 2: Role interactivity in retention of subject (Agree: $78 \%$ )

Category 3: Improved attention span due to interactivity (Agree: 84\%)

Category 4: Recommend the use of interactivity in all lectures (Agree: 83\%)

Category 5: Liked interactive lectures (Agree: 88\%)

Table-1 : Suggestions from the students.

\begin{tabular}{|l|}
\hline Interactive lectures in every class \\
\hline Case based learning is needed \\
\hline More Integrated teaching \\
\hline Some time class become boring if extended too much \\
\hline Inclusion of MCQ base questions in final exams \\
\hline Assessment should be done in between \\
\hline Black boards and chalk can be used \\
\hline
\end{tabular}

Table-2: Comments of the students.

\begin{tabular}{|l|}
\hline The approach to teaching is very nice \\
\hline Improves understanding the subject and retention of topic \\
\hline This encouraged us a lot, to come prepared before the lecture \\
\hline Team work in groups made us to study more in short time \\
\hline Group discussions helped in improving our communication skills \\
\hline Questions were entertained and students " participation was encouraged \\
\hline Atmosphere was livelier, making us active and attentive in class \\
\hline It has helped us to prepare for Pre-PG entrance exams \\
\hline
\end{tabular}

\section{Discussion}

The purpose of teaching is to facilitate learning and encourage the learners to learn more effectively. Interactive teaching involves interchange of ideas between teachers, students and the lecture content. It refers to increased discussion among the participants and their active involvement. Interactive teaching involves a two-way interaction between the presenter and the participants. 
It encourages and expects learners to participate. It values student's prior ideas and aims at empowering students to be independent learners.

The vision of a teacher using an interactive approach is to develop classrooms, where students are helped to make sense and reflect on their experiences, evaluate their work and set future learning goals. In such classrooms students are encouraged to articulate how they learn, they should be able to express what the problem is they working on, what questions and prior ideas they have what their plans are to solve the problem $[2,3]$.

Interactive teaching is the term given to a strategy/style of teaching. For teachers it offers an opportunity to learn along with the students and to use their interactive skills to listen carefully and challenge misconceptions where possible. The teacher's own knowledge will always be an important factor. There are likely as many teaching methods and techniques as there are teachers, but some stand out due to their effectiveness. Both teachers and students will enjoy class more when it includes methods that encourage students to take responsibility for their own learning and a more active role in and out of the classroom $[2,3]$.

A number of interactive teachings and assessment methods were undertaken for theory and practical's sessions. Practical's sessions were conducted by making small groups (9 students/group) and allowing case based group discussions, crossword puzzles, think-pair-share, one minute paper and Playing Card - Viva-voce. In theory classes' cinemeducation, integrated teaching, seminars, Quiz, brain storming, confusion technique, question answer sessions, think-pair-share and multiple choice questions (MCQ's) were introduced in the pathology curriculum. In study done by Buch et al students liked MCQs the most followed by brain storming and confusion technique, where as in our study students liked the MCQs the most followed by jig-saw learning and cross-word puzzle [4].

MCQs in between the lectures break the monotony and activate students' interaction. It is less time consuming, Pre-PG entrance exam oriented and also can act as a problem solving tool. Brainstorming act as a problem based learning, activates the students to think and activate decision making ability. It can make a very good start of the lecture and make it interesting. Confusion technique at the end helps to clear doubts.
This is useful especially to students who are scared to ask the doubts in public. It also acts like a small group activity with fun. Though we found that students appreciated MCQs the most, different types of interactivity should be carried out at the appropriate interval as per teacher's discrimination with the basic aim to make the session more interactive. We also introduced the concept of team work during the practical's by dividing the students in groups as done by Buch et al. Teamwork was highly appreciated by students as seen by Buch et al [4]. Borkar et al [5] introduced interactivity in community medicine \& Buch AC et al [4] introduced in Pathology and found that all most all students were in favour of interactive lecture. The most liked teaching learning method was a small group discussion $76 \%$ in Borkar et al[5], 75\% in Buch AC et al and it was $92 \%$ in our study.

In our results students found it difficult to correlate the related concepts and integrate the different subjects. However when they were made aware about integrated method of teaching, majority felt that the system could be useful and time saving, consistent with the results of study carried out by Kate et al.[6] Studies have shown that it was well received by the students and faculty as well and found to be effective to enhance the skill of clinicpathological correlation and help to improve the cognitive and psychomotor domains of the students. [6] Interactive teaching for medical students helps in understanding the subject, more retention of the facts and clarification of the doubts in a lively environment, which helps them to apply in clinical practice.

Quiz format which was done as per clinicpathological correlation, Multiple choice questions, pictorials, clinical images, instruments and microphotograph slides from hematology, cytology, histopathology helps in getting good rank in the online post graduate entrance examinations. And by adopting this type of curriculum, students will improve their clinical knowledge and communication skills. This will also make the teaching and le; arning process in the medical sciences more effective and relevant to the health of the society.

\section{Conclusion}

This project clearly proves that revised/updated pathology curriculum which included interactive teaching and assessment methods are definitely preferred by the 2nd M.B.B.S students in learning pathology. 
MCQ's and Cinemeducation were the most liked interactive sessions. So, we want to conclude by saying that a "Teacher should take a new role of a Facilitator" for facilitating the process of interactive learning rather than delivering elaborative lectures.

\section{Contributions}

Dr. Mahesh Kumar $U$ and Dr. Pankaj Pande both conceived and planned the experiments. Miss. Prasanna carried out the experiments. Miss. Prasanna contributed to sample preparation. Dr. Mahesh Kumar U, Dr. Pankaj Pande and Miss Prasanna contributed to the interpretation of the results. Dr. Mahesh Kumar U and Dr. Pankaj Pande took the lead in writing the manuscript. All the authors provided critical feedback and helped shape the research, analysis and manuscript.

\section{Acknowledgements}

Dr. Anandam. G, Prof \& HOD Pathology, Dr. Sharadrutha Prasad, Prof. Pathology, Dr. Srikanth S, Prof Pathology, All Post graduate students and technical staff of PIMS, Karimnagar for their help and co-operation.

\section{Reference}

01. Shah AR, Shethwala ND, Parmar BH. Perception of undergraduate medical students towards the subject of pathology at one of the medical colleges of Gujarat, India. International Journal of Medical Science and Public Health. 2014;3(7)863-865.

[Crossref]

02. Mohamed EL-Bab Fath EL-Bab, Bassem Sheikh, Sherin Shalaby, Mohamed EL-Awady, Abbas Allam. Evaluation of Basic medical sciences knowledge retention among medical students. Ibnosina Journal of Medicine and Biomedical Sciences. 2011;3(1)45- 52.

[Crossref]

03. Vanishree BJ, Nayaka R, Manjunath $S$. Somannavar, Sonoli SS. The perception of MBBS interns towards biochemistry Curriculum in a south Indian Medical College. NJIRM.

2016;7(4) 82-86 [Crossref]
04. Arachana C Buch, Chandanwala SS, Bamnikar SA. Interactive teaching- Understanding perspectives of II MBBS students in Pathology. Medical Journal of DY Pat University. Nov-Dec 2014;7(6)693-695.

[Crossref]

05. Borkar RS, Meshram SA, Jadhav PE. Introducing interactivity in community medicine classes for arousing interest in the subject amongst IInd MBBS students. Res Anal Eval. 2012;4;47-8.

[Crossref]

06. Kate MS, Kulkarni UJ, Supe A, Deshmukh YA. Introducing integrated teaching in undergraduate medical curriculum. International Journal of Pharma Sciences and Research. 2010;1(1)18-22.

[Crossref] 